\title{
Correlating nurses' levels of Psychological Capital with their reward preferences and reward satisfaction
}

\begin{tabular}{|c|c|}
\hline \multicolumn{2}{|c|}{$\begin{array}{l}\text { Authors: } \\
\text { Stacy A. Shelton }{ }^{1} \\
\text { Michelle Renard }^{1}\end{array}$} \\
\hline \multicolumn{2}{|c|}{$\begin{array}{l}\text { Affiliations: } \\
{ }^{1} \text { Department of Industrial } \\
\text { and Organisational } \\
\text { Psychology, Nelson Mandela } \\
\text { Metropolitan University, } \\
\text { South Africa }\end{array}$} \\
\hline \multicolumn{2}{|c|}{$\begin{array}{l}\text { Correspondence to: } \\
\text { Stacy Shelton }\end{array}$} \\
\hline \multicolumn{2}{|c|}{$\begin{array}{l}\text { Email: } \\
\text { stacyann.shelton@gmail.com }\end{array}$} \\
\hline \multicolumn{2}{|c|}{$\begin{array}{l}\text { Postal address: } \\
\text { PO Box 77000, Nelson } \\
\text { Mandela Metropolitan } \\
\text { University, Port Elizabeth } \\
6031 \text {, South Africa }\end{array}$} \\
\hline \multicolumn{2}{|c|}{$\begin{array}{l}\text { Dates: } \\
\text { Received: } 06 \text { Feb. } 2015 \\
\text { Accepted: } 19 \text { May } 2015 \\
\text { Published: } 16 \text { Sept. } 2015\end{array}$} \\
\hline \multicolumn{2}{|c|}{$\begin{array}{l}\text { How to cite this article: } \\
\text { Shelton, S.A., \& Renard, M. } \\
\text { (2015). Correlating nurses' } \\
\text { levels of Psychological } \\
\text { Capital with their reward } \\
\text { preferences and reward } \\
\text { satisfaction. SA Journal of } \\
\text { Industrial Psychology/SA } \\
\text { Tydskrif vir Bedryfsielkunde, } \\
41(1), \text { Art. \#1271, 14 pages. } \\
\text { http://dx.doi.org/10.4102/ } \\
\text { sajip.v41i1.1271 }\end{array}$} \\
\hline \multicolumn{2}{|c|}{$\begin{array}{l}\text { Copyright: } \\
\text { (C) 2015. The Authors. } \\
\text { Licensee: AOSIS } \\
\text { OpenJournals. This work is } \\
\text { licensed under the Creative } \\
\text { Commons Attribution } \\
\text { License. }\end{array}$} \\
\hline \multicolumn{2}{|l|}{ Read online: } \\
\hline 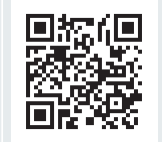 & $\begin{array}{l}\text { Scan this QR } \\
\text { code with your } \\
\text { smart phone or } \\
\text { mobile device } \\
\text { to read online. }\end{array}$ \\
\hline
\end{tabular}

Orientation: Psychological Capital (PsyCap) is crucial for the effective performance of nurses, and may be influenced by rewarding employees according to their individual preferences.

Research purpose: The purpose of this study was to establish whether relationships exist between nurses' levels of PsyCap and both their reward preferences and levels of reward satisfaction. It also aimed to investigate whether demographic differences occurred across these variables.

Motivation for the study: Currently there is limited research relating to PsyCap within the South African context, and none to date specifically related to the medical industry in South Africa. Moreover, it is vital that the reward preferences of nurses are taken into account when designing their rewards packages, in order for them to be satisfied within their respective medical institutions.

Research approach, design and method: This quantitative study was conducted using nonprobability sampling, with 116 nurses within the public and private sectors of the Nelson Mandela Metropole medical industry completing the questionnaire. The instruments utilised were the Psychological Capital Questionnaire and the Reward Preferences Questionnaire.

Main findings: It was found that the majority of the sample exhibited high levels of PsyCap. Correlations existed between PsyCap factors and certain reward preference and reward satisfaction factors. Significant differences occurred across the demographic variables of age, marital status, education level, tenure and sector.

Practical/managerial implications: In order to maintain high PsyCap levels and ensure that nurses are satisfied, medical institutions should take individual reward preferences into account and reward their nurses accordingly.

Contribution/value-add: These findings add to the current body of South African literature regarding PsyCap and reward preferences, and provide valuable insight into the use of rewards in improving levels of PsyCap within the medical setting. The consideration of nurses' reward preferences when designing rewards packages can lead to enhanced PsyCap and improved reward satisfaction amongst nurses, possibly resulting in enhanced patient care.

\section{Introduction}

Nursing is an incredibly important profession to study as nurses' performance will have a great impact on the care provided to patients (Othman, Ghazali \& Ahmad, 2013). BeševićĆomić, Bosankić and Draganović (2014) state that nurses may experience high levels of job exhaustion and work overload and this provides an explanation as to why there is currently a global problem with nurses experiencing burnout. These authors provide evidence that nurses are experiencing low to moderate levels of burnout and high levels of depersonalisation in the service they provide to their patients. However, Peng et al. (2013) state that nurses who are hopeful, optimistic, resilient and have high levels of self-efficacy (that is, exhibit high levels of Psychological Capital - PsyCap) are more likely to excel at work and have positive work attitudes, and are less likely to depersonalise their service and experience burnout. Wang, Chang, Fu and Wang (2012) also provide evidence that PsyCap may drastically decrease levels of burnout experienced by nurses.

Avey, Luthans and Jensen (2009) explain that PsyCap largely involves organisations concentrating on employees' strengths and developing their weaknesses, rather than focusing on their vulnerabilities. Luthans, Youssef and Avolio (2007), as cited by Luthans, Norman, Avolio and Avey (2008), describe PsyCap as an individual's positive mental state of development, which is characterised by having the confidence to take on challenging tasks (self-efficacy) and making a positive attribution about succeeding now and in the future (optimism). PsyCap also includes 
persevering towards goals and specifying paths to goals in order to succeed (hope) as well as sustaining and 'bouncing back' from problems or adversity in order to attain success (resiliency). Self-efficacy is defined as an individual's belief about their abilities to mobilise the motivation, cognitive resources and courses of action required to successfully execute a specific task within a given context (Stajkovic \& Luthans, 1998), whereas hope is defined by Snyder (2002, p. 249) as 'the perceived capability to derive pathways to desired goals, and motivate oneself via agency thinking to use those pathways'. Moreover, Luthans (2012) defines optimism as a process in which internal attributions for success are triggered and a sense of positive expectations for the future develops. Finally, resilience is defined as 'the positive psychological capacity to rebound, to "bounce back" from adversity, uncertainty, conflict, failure, or even positive change, progress, and increased responsibility' (Luthans, 2002a, p. 702).

As employees are individuals, they will have different demands and needs, and thus their reward preferences differ. Rewards are described by Chen and Hsieh (2006) as everything that employees perceive to be valuable as a result of the employment relationship. It typically includes cash compensation and benefits, as well as other non-cash rewards and the work experience (Chen \& Hsieh, 2006). According to Linkow (2006) one way in which organisations can respond to the demands of employees is to begin to understand their reward preferences. Moore and Bussin (2009) highlight the importance of having remuneration packages that are tailored to the needs of the organisation's employees by stating that this is likely to result in high levels of performance and overall job satisfaction.

Chiang and Birtch (2012) state that reward preferences stem from a combination of motivations, preferences and values, and this may account for why reward preferences may be so varied from person to person. As stated by Thumbran (2010), organisations have developed an approach towards rewards that involves the use of a total rewards package that includes both financial and non-financial rewards. Examples of financial rewards include base pay, contingency pay and benefits, whereas examples of non-financial rewards include recognition, flexible work schedules and training and development opportunities (Chiang \& Birtch, 2012).

The authors state that when employees receive their respective reward preferences, it is likely that they will exhibit higher levels of reward satisfaction, which in turn may result in increased job satisfaction. However, Fin24 (2014a) reports that staff from private hospitals are unhappy with their current remuneration, and Fin24 (2014b) revealed that private hospital nurses feel that they are overworked and underpaid. These findings reiterate the importance of adequate pay within the medical industry. Additionally, Ehlers and Oosthuizen (2011) conducted a study on a sample of 108 nurses within South Africa, which revealed that the reward that nurses most prefer is a high level of base pay, followed closely by a quality work environment. Satisfying such preferences will prove to be problematic based on the above reported by Fin24.

Based on the fact there is no prior research linking these three constructs to one another, the authors propose that high levels of PsyCap, as well as its subcomponents, are likely to impact employees' levels of reward satisfaction. Moreover, the provision of employees' respective reward preferences may in turn influence their levels of PsyCap.

\section{Research purpose and objectives}

It is clear from the above overview that high levels of PsyCap are advantageous for nurses, and that nurses have differing reward preferences and experience differing levels of satisfaction with their current rewards. This justifies the need for the present research study, which investigates these three constructs within the Nelson Mandela Metropole medical industry in South Africa. Ardichvili (2011) believes that whilst there is much relevance in the construct of PsyCap in that it holds many benefits for employees, there is still much room for research in countries outside the United States. To date, few PsyCap studies (see Görgens-Ekermans \& Herbert, 2013; Harris, 2012; Schoeman, 2012) and reward preferencestudies(seeNienaber,Bussin\&Henn,2011;Snelgar, Renard \& Venter, 2013) have been conducted in South Africa. Furthermore, there have been no studies conducted to date that link either the reward preferences of employees or their levels of reward satisfaction with their levels of PsyCap.

Based on the above, the primary purpose of this study is to address the gap in empirical research by investigating the relationship between PsyCap and both reward preferences and satisfaction in the Nelson Mandela Metropole medical industry in South Africa. Additionally, differences across demographics such as age, educational level and tenure for these three constructs will be investigated.

In order to achieve these objectives, this article will provide a brief literature review outlining PsyCap and reward preferences and satisfaction, followed by the research design for this study. Thereafter, a discussion of the results will be provided, which will address the study's purpose and objectives.

\section{Literature review Psychological Capital}

Luthans et al. (2008) state that PsyCap is typically 'state-like' in the sense that it is believed that PsyCap is moderately stable, but not fixed in the way that personality or a core self-evaluation may be. Luthans, Avey, Avolio and Peterson (2010) mention, however, that the PsyCap constructs are more stable than moods or emotions. PsyCap is therefore not the same as positive emotions or feelings, but is rather a positive state. 
Avey (2014) mentions that there is a strong correlation between employees' levels of PsyCap, their resulting levels of performances and their patterns of behaviour, thus suggesting that PsyCap has the ability to positively influence employees. Individuals who have higher levels of PsyCap are more likely to be energised and thus put forth effort, which results in improved performance over an extended period of time (Avey, 2014). Avey, Reichard, Luthans and Mhatre (2011) identified strong correlations between job satisfaction and PsyCap. These authors note that when employees experience reward satisfaction they are more likely to have an expectancy of success, which stems from having optimism, and a belief in their personal abilities, which is derived from self-efficacy and hope. Furthermore, individuals who recover well from setbacks (resilience) have been proven to be more satisfied with their rewards (Avey, 2014). The four dimensions of PsyCap will now be discussed in more detail as they specifically relate to an individual's behaviour.

\section{Self-efficacy}

Luthans (2002b) states that confidence and self-efficacy are very similar in nature. Both Luthans and Bandura (1982) note that individuals with higher levels of self-efficacy are more likely to elect to attempt a challenging task (such as training and development) and will apply more effort, be more motivated to complete a task and be more persistent when obstacles are encountered. This, therefore, suggests that employees with higher levels of self-efficacy are more open to challenges and self-development due to their beliefs that they will succeed in such activities.

\section{Hope}

Lazarus (1999) states that the most basic requirement for hope is that an individual should be dissatisfied in some way with their current circumstances and should wish to improve them. This then leads to the setting of goals to change the circumstances they find themselves in. Snyder (2002) states that when individuals have hope, they may often reach for 'grand' goals. Therefore, this suggests that individuals who are hopeful are likely to stretch themselves, seek goals that will improve them as individuals and place higher demands on themselves.

\section{Optimism}

Optimism within the context of PsyCap is realistic optimism. Schneider (2001) describes realistic optimism as maintaining a positive outlook within the constraints of the available and measurable phenomena within the physical and social world. Scheier and Carver (1985) note that whilst self-efficacy is the belief specifically in one's own abilities to complete a task, optimism views a multitude of factors, both internal and external, as being responsible for a favourable outcome. An internal factor may include the belief in one's own capabilities and external factors may include supportive work colleagues or good working relationships (Scheier \& Carver, 1985). Schneider states that optimistic individuals have a tendency to seek out opportunities for the future. Therefore, this author suggests that optimistic individuals are more likely to take on challenges and seek personal development. Fracaro (2001) mentions that individuals that are optimistic are more likely to be interested in learning new things through continuous development and will be more confident in their abilities to handle challenges, thus being willing to take on such challenges.

\section{Resilience}

Luthans, Luthans and Avey (2014) state that individuals with high levels of resilience will generally cope better with mistakes, setbacks and failures. These authors mention that individuals who are resilient do not become emotionally distracted, but rather they take on new challenges and attempt to recover from mistakes. Luthans and Youssef (2007) mention that resilience allows for both reactive recovery from failure and proactive learning and growth through new challenges. The same authors mention that resilience causes individuals to bounce back from failures and develop more strategic behaviour than before. In so doing, the individual may gain personal development and career advancement (Luthans \& Youssef, 2007).

\section{Reward preferences and satisfaction}

Allen and Helms (2001) highlight the importance of effective reward practices by stating that these have the potential to improve motivation, which leads to an increase in employee performance and ultimately an increase in the organisation's performance. It is for this reason that an organisation's reward practices should be of a high standard. In order to motivate employees, it is crucial that organisations address the needs of their employees through a holistic, integrated and business-aligned approach to the management of rewards for employees (Nienaber et al., 2011). In order to do this, an organisation needs to respond to the demands of their employees by gaining an understanding of their reward preferences (Linkow, 2006). It is this discovery that has led to organisations adopting a total rewards strategy.

The Achievement Awards Group (2008) defines total rewards as an integrated approach to managing an organisation's human resources, which considers the strategic interdependence of both tangible and non-tangible factors that impact on employees' levels of motivation. Kwon and Hein (2013) highlight the importance of total rewards by stating that employees do find financial rewards to be important, but it is a combination of appealing factors that will make an employment deal attractive to an employee. This, therefore, creates a need for total rewards.

Nienaber et al.'s (2011) Total Rewards framework forms the basis of this study. This framework includes both financial and non-financial rewards. According to Nienaber et al., financial rewards incorporate compensation (fixed pay or 
salary), benefits (such as medical aid and pension funds) and contingency pay (such as variable pay and performancebased pay). Chiu, Luk and Tang (2002) note that employees will view the financial rewards that they receive from their organisation as an indication of their value to the organisation, and for this reason financial rewards play a large role in reward management. However, Zobal (1999) states that there are many problems associated with financial rewards. These include the fact that they cause employees to shift their focus only towards achieving financial gain. This may, therefore, move their focus away from developing themselves to being mainly focused on completing a task for financial gain (Zobal, 1999). Furthermore, Zobal states that financial rewards may lead to negative effects on employees when goals are not achieved, such as a lack of confidence or being demotivated.

On the other hand, Nienaber et al. (2011) state that nonfinancial rewards include work-life integration (such as flexitime, job sharing and wellness programmes), career and performance management (including performance appraisals and training and development opportunities) and a quality work environment (such as adequate physical resources and meaningful working relationships). Nonfinancial rewards are often referred to as internal rewards as they meet the internal needs of an employee more so than financial rewards (Thumbran, 2010). Nienaber et al. state that employees seek more meaningful rewards from their work and it is for this reason that they are likely to place a great value on non-financial rewards. Furthermore, Dewhurst, Guthridge and Mohr (2009) state that non-financial rewards lead to employees feeling more positive, as well as feeling that the organisation values their well-being.

Boyd and Salamin (2001) state that an organisation's employees form the basis of any organisation's competitive advantage due to the fact that human resources are more durable and less likely to be imitated than any other organisational assets. Thus, they note that an effective compensation plan that accounts for employees' individual reward preferences is essential in order to effectively attract, motivate and retain the best employees. Attracting the right employees, and motivating and retaining these employees, is crucial to developing a competitive advantage for the organisation. Through focusing on the reward preferences of employees, they are more likely to become motivated and more committed to the organisation as a result (Kaliprasad, 2006).

\section{Demographic differences in PsyCap}

As previously mentioned, within South Africa there are limited studies that relate to PsyCap. However, Harris (2012) reported no statistically significant differences between individuals on the basis of tenure or age with regard to PsyCap. Furthermore, Rauschenbach, Göritz and Hertel (2012) revealed that with regard to resilience (a subscale of PsyCap) generally older employees have higher levels of resilience than their younger counterparts owing to their wealth of work experience.

\section{Demographic differences in reward preferences and reward satisfaction}

Nienaber et al. (2011) provide evidence of multiple correlations between reward preferences and demographic variables. Amongst these were that both performance and career management and a good working environment are preferred mainly by individuals with no formal postgraduate qualifications. Additionally, they state that work-life integration is preferred by younger, married employees with postgraduate qualifications. Snelgar et al. (2013) concur that younger employees indicate a distinct preference for work-life integration as a reward. Specifically within nursing, Von Bonsdorff (2011) revealed that younger nurses show a distinct preference for work-life integration as a reward. Finally, Nienaber et al. note that individuals with postgraduate qualifications will show a significantly higher preference for benefits and base pay based on their high expectations due to their higher qualifications. Specifically within nursing, Von Bonsdorff (2011) notes that older employees with longer tenure are typically less satisfied with their financial rewards than their younger counterparts.

\section{Research design}

\section{Research approach}

The empirical research conducted for this study was nonexperimental in nature and followed a cross-sectional quantitative approach. The authors adopted this approach in order to determine whether statistically significant patterns of preferences would emerge, which would not have been possible if a qualitative approach were adopted.

\section{Research method \\ Research participants}

The sample for this study was derived from nurses within a local branch of a national private sector hospital group, as well as from a local public hospital, within Nelson Mandela Metropole. Furthermore, nurses and care workers from a local non-profit organisation, a nursing agency and a local frail care centre were included, in order to increase the sample size.

The sampling technique used was non-probability sampling. Malhotra (2010) states that non-probability sampling relies on the judgement of the authors to administer the questionnaires; therefore, not all members in the population have an equal chance of being selected. Three types of nonprobability sampling were used in order to improve the sample size, namely purposive, snowball and convenience sampling. Welman, Kruger and Mitchell (2005) describe purposive sampling as the process through which a researcher deliberately obtains units of analysis in such a way that the sample may be regarded as representative 
of the relevant population from which it is drawn. Only individuals who worked within the selected organisations and had some dealing with patients were included in the sample. Malhotra states that snowball sampling occurs when an initial group of respondents is selected and subsequent respondents are selected thereafter on the basis of referrals. Finally, convenience sampling attempts to obtain a sample comprised of convenient elements by using the judgement of the researcher (Malhotra, 2010).

The total number of questionnaires distributed was 273 and 116 questionnaires were returned. Therefore, the response rate was $42 \%$. However, response errors occurred when respondents completed the Rewards Preferences Questionnaire (RPQ), with some nurses not indicating responses for certain questions. For this reason, the total number of respondents was 106 for certain sections of the RPQ. Additionally, not all respondents answered every demographic question, resulting in the total number of respondents being 112 for education level, 114 for job level and 115 for tenure.

\section{Characteristics of the sample}

Table 1 displays the biographical characteristics of the sample. The majority of the sample comprised individuals aged 49 and older (51\%); $57 \%$ of the sample was married. Furthermore, the majority of the sample had some form of tertiary education (56\% with a diploma or degree and $20 \%$ with a postgraduate qualification). The sample was divided into two job levels: administrative nurses and nonadministrative nurses. Administrative nurses included those who perform administrative and clerical functions, as well as medical staff in the positions of junior, senior and general management. Non-administrative nurses included those who are registered specialists and care workers and are working only with patients. The sample comprised $77 \%$ non-administrative nurses with the remaining $23 \%$ being administrative nurses. The majority of the sample (45\%) had more than 10 years of service with their current organisation. Finally, 49\% of respondents worked within

TABLE 1: Biographical characteristics of the sample.

\begin{tabular}{llll}
\hline Variable & Item & $\boldsymbol{f}$ & $\mathbf{\%}$ \\
\hline Age & $18-38$ years & 24 & 21 \\
& 39-48 years & 33 & 28 \\
Marital status & 49+ years & 59 & 51 \\
& Married & 66 & 57 \\
& Single & 27 & 23 \\
Educational level & Divorced/separated/widowed & 23 & 20 \\
& Matric or less & 27 & 24 \\
& Diploma/degree & 63 & 56 \\
Job level & Postgraduate & 22 & 20 \\
& Administrative & 26 & 23 \\
Tenure & Non-administrative & 88 & 77 \\
& 0-4 years & 34 & 30 \\
& 5-10 years & 29 & 25 \\
Sector & 10+ years & 52 & 45 \\
& Public & 57 & 49 \\
\hline
\end{tabular}

$f$, frequency the public sector, whereas the remaining $51 \%$ worked in the private sector.

\section{Measuring instruments}

The composite questionnaire used for this study was a fixed-answer questionnaire, requiring respondents to select from a series of predetermined answers (Malhotra, 2010). It consisted of a biographical data section and two measuring instruments, namely the Psychological Capital Questionnaire (PCQ) and the RPQ.

\section{The Psychological Capital Questionnaire}

The PCQ was developed by Luthans, Avolio and Avey (2007) and is comprised of 24 items measuring four subscales, namely self-efficacy, hope, resilience and optimism. Each subscale is measured by six items. The PCQ items are measured using a six-point Likert scale. The responses range from 1 (strongly disagree) to 6 (strongly agree). In the South African context, Harris (2012) found the PCQ to have an overall reliability score of 0.86 , Schoeman (2012) an overall reliability score of 0.88 and Görgens-Ekermans and Herbert (2013) an overall reliability score of 0.85 , thus indicating high levels of reliability. The PCQ exhibits both content and construct validity, since its subscales measure PsyCap accurately, and have been developed from various literature theories relating to self-efficacy, hope, resilience and optimism.

\section{The Reward Preferences Questionnaire}

Nienaber et al.'s (2011) RPQ was based upon the Total Rewards Framework developed by WorldatWork (2006). For the purposes of this study, the modified instrument utilised by Snelgar et al. (2013) was employed. The modified instrument uses a five-point Likert scale, instead of the original seven-point Likert scale. The questionnaire is comprised of two sections: reward preferences and satisfaction with the rewards received from the respondent's current employer. The reward preferences section includes a scale with responses ranging from 1 (not important at all) to 5 (extremely important). With regard to the satisfaction section, 1 represents highly dissatisfied and 5 represents highly satisfied. The RPQ has six subscales, namely base pay, contingency pay, benefits, performance and career management, quality work environment and work-life integration. In the South African study conducted by Nienaber et al., the overall Cronbach's alpha score was 0.84 , thus proving a high level of reliability. In the study conducted by Snelgar et al., also within the South African context, the reliability scores for the preference factors were 0.66 (base pay), 0.52 (contingency pay), 0.73 (benefits), 0.82 (performance and career management), 0.68 (quality work environment) and 0.69 (work-life integration). For the satisfaction factors, the reliability scores were 0.87 (base pay), 0.78 (contingency pay), 0.74 (benefits), 0.88 (performance and career management), 0.71 (quality work environment) and 0.72 (work-life integration), thus also indicating high levels of reliability. Furthermore, the RPQ was found in both studies to have content and construct validity. 


\section{Research procedure and ethical considerations}

The data was collected through the use of pencil and paper questionnaires, since not all respondents in the sample had access to the Internet to complete an online questionnaire. The questionnaires were left at all the medical institutions included in the sample and the authors were reliant on the managers of each institution to distribute the questionnaires. After a period of four weeks, the authors collected the questionnaires from the various sampled institutions.

The authors obtained formal permission from the relevant head offices to conduct research in the public and private hospitals that formed part of the sample. In addition, permission was granted from Mind Garden, the publishers of the PCQ, to make use of the instrument for academic purposes, provided that it remained unmodified. To ensure the ethicality of the study, participation was completely voluntary. None of the respondents was forced to participate and no incentives were provided to encourage participation. Additionally, all responses were anonymous. The data obtained from the respondents remained confidential and were only accessed by the authors and the study's statistician.

\section{Statistical analysis}

Statistical analysis was completed through the use of both descriptive and inferential statistics. The data was analysed using a statistical software applications package that was developed by the authors' statistician from the Unit for Statistical Consultation at NMMU. Cronbach's alpha coefficients were calculated in order to prove that the instruments were reliable. Descriptive statistics were calculated in the form of frequency distribution tables, as well as through measures of central tendency and dispersion, in order to illustrate general trends within the data analysis.

In terms of inferential statistics, Pearson's product moment correlations were utilised to attempt to establish a relationship between the subscales of the PCQ and the RPQ. This technique is used to establish the strength of the correlations between factors (Malhotra, 2010). t-Tests were used to assess whether statistically significant differences existed between sector and job level across the subscales of the PCQ and the RPQ. Analysis of variance (ANOVA) was utilised to establish whether there were any statistically significant differences between age, marital status, educational level and tenure across the subscales of the PCQ and the RPQ. Post-hoc Scheffé tests were used when a level of statistical significance was found. Thereafter, Cohen's $d$ was calculated in order to determine the level of practical significance.

\section{Results \\ Descriptive statistics and Cronbach's alpha coefficients}

Table 2 summarises the descriptive statistics for the PCQ and the RPQ by providing the minimum, maximum, mean, standard deviation and Cronbach's alpha values for the constructs under study. It is evident that the nurses within the sample exhibited high levels of total PsyCap, with an overall mean of 4.66 out of a possible 6.00 . The two greatest reward preferences were for a quality work environment and base pay, whereas their greatest satisfaction was with a quality work environment and performance and career management.

Both measuring instruments exhibited acceptable internal reliability as the Cronbach's alpha values are above the 0.60 level (Malhotra, 2010): the reliability coefficient for the total reward preferences section is 0.89 and the total satisfaction section is 0.90 . The reliability coefficient for the total PCQ is 0.81 . The authors note that the Cronbach's alpha values for the RPQ factors of preference for base pay, preference for contingency pay, preference for benefits, preference for performance and career management and preference for worklife integration are higher than those found by Snelgar et al. (2013). Additionally, satisfaction with benefits, satisfaction with

TABLE 2: Descriptive statistics and reliability coefficients for Reward Preferences Questionnaire (RPQ) and Psychological Questionnaire (PCQ).

\begin{tabular}{|c|c|c|c|c|c|c|}
\hline Instrument & Factors & Mean & Standard deviation & Minimum & Maximum & Cronbach's alpha \\
\hline \multirow[t]{7}{*}{ RPQ: Reward preference } & Base pay & 3.99 & 0.68 & 1.00 & 5.00 & 0.82 \\
\hline & Contingency pay & 3.70 & 0.77 & 1.00 & 5.00 & 0.69 \\
\hline & Benefits & 3.82 & 0.79 & 1.50 & 5.00 & 0.88 \\
\hline & Performance and career management & 3.82 & 0.61 & 1.15 & 5.00 & 0.89 \\
\hline & Quality work environment & 4.07 & 0.49 & 3.00 & 5.00 & 0.66 \\
\hline & Work-life integration & 3.23 & 0.73 & 1.00 & 5.00 & 0.76 \\
\hline & Total reward preference & 3.77 & 0.55 & 1.66 & 5.00 & 0.89 \\
\hline \multirow[t]{7}{*}{ RPQ: Reward satisfaction } & Base pay & 2.66 & 0.74 & 1.00 & 4.20 & 0.81 \\
\hline & Contingency pay & 2.68 & 0.75 & 1.00 & 4.75 & 0.72 \\
\hline & Benefits & 2.89 & 0.57 & 1.00 & 3.88 & 0.78 \\
\hline & Performance and career management & 3.00 & 0.65 & 1.15 & 4.38 & 0.90 \\
\hline & Quality work environment & 3.25 & 0.65 & 1.00 & 4.33 & 0.79 \\
\hline & Work-life integration & 2.68 & 0.73 & 1.00 & 5.00 & 0.84 \\
\hline & Total reward satisfaction & 2.86 & 0.56 & 1.18 & 3.93 & 0.90 \\
\hline \multirow[t]{5}{*}{ PCQ } & Self-efficacy & 4.73 & 0.66 & 3.00 & 4.83 & 0.72 \\
\hline & Hope & 4.73 & 0.73 & 3.00 & 4.83 & 0.79 \\
\hline & Resilience & 4.65 & 0.70 & 2.50 & 4.67 & 0.71 \\
\hline & Optimism & 4.50 & 0.58 & 3.33 & 4.50 & 0.46 \\
\hline & Total PsyCap & 4.66 & 0.53 & 3.13 & 4.71 & 0.81 \\
\hline
\end{tabular}


TABLE 3: Pearson's product moment correlation coefficients for PCQ and RPQ preference factors.

\begin{tabular}{|c|c|c|c|c|c|c|c|}
\hline Variable & Base pay & Contingency pay & Benefits & $\begin{array}{l}\text { Performance and } \\
\text { career management }\end{array}$ & $\begin{array}{l}\text { Quality work } \\
\text { environment }\end{array}$ & $\begin{array}{l}\text { Work-life } \\
\text { integration }\end{array}$ & $\begin{array}{c}\text { Total reward } \\
\text { preference }\end{array}$ \\
\hline Efficacy & 0.002 & 0.024 & -0.066 & 0.134 & 0.103 & 0.110 & 0.047 \\
\hline Hope & $-0.259 *$ & 0.033 & -0.148 & -0.044 & -0.017 & -0.156 & -0.150 \\
\hline Resilience & -0.164 & 0.022 & -0.102 & 0.029 & 0.070 & -0.066 & -0.075 \\
\hline Optimism & -0.109 & 0.003 & $-0.266^{*}$ & -0.073 & -0.096 & -0.062 & -0.137 \\
\hline Total PsyCap & -0.174 & 0.023 & -0.182 & 0.016 & 0.022 & -0.056 & -0.102 \\
\hline
\end{tabular}

PCQ, Psychological Capital Questionnaire; RPQ, Reward Preferences Questionnaire

$*_{r}>0.191=$ statistically significant; $* * r>0.30=$ practically significant.

TABLE 4: Pearson's product moment correlations for PCQ and RPQ satisfaction factors.

\begin{tabular}{|c|c|c|c|c|c|c|c|}
\hline Variable & Base pay & Contingency pay & Benefits & $\begin{array}{l}\text { Performance and } \\
\text { career management }\end{array}$ & $\begin{array}{l}\text { Quality work } \\
\text { environment }\end{array}$ & $\begin{array}{l}\text { Work-life } \\
\text { integration }\end{array}$ & $\begin{array}{l}\text { Total reward } \\
\text { satisfaction }\end{array}$ \\
\hline Efficacy & 0.116 & -0.017 & 0.088 & $0.188^{*}$ & -0.001 & 0.092 & 0.091 \\
\hline Hope & $0.204 *$ & -0.001 & 0.185 & $0.256 *$ & 0.081 & 0.103 & 0.167 \\
\hline Optimism & 0.158 & 0.129 & 0.040 & $0.210 *$ & 0.146 & $0.228 *$ & $0.187 *$ \\
\hline Total PsyCap & $0.190 *$ & 0.028 & 0.145 & $0.261 *$ & 0.090 & 0.178 & 0.181 \\
\hline
\end{tabular}

PCQ, Psychological Capital Questionnaire; RPQ, Reward Preferences Questionnaire

$*_{r}>0.187=$ statistically significant; $* * r>0.30=$ practically significant.

performance and career management, satisfaction with quality work environment and satisfaction with work-life integration are all higher than the reliability coefficients obtained in Snelgar et al.'s study. However, for the factors of the PCQ, all the factors in the present study, with the exception of resilience, obtained lower reliability coefficients than in previous studies conducted by Harris (2012), Schoeman (2012) and Görgens-Ekermans and Herbert (2013).

\section{Relationship between PCQ and RPQ factors}

From Table 3 it is evident that there is a statistically significant negative relationship between base pay as a reward preference and hope, and a statistically significant negative relationship between benefits as a reward preference and optimism. Therefore, this implies that if respondents exhibit a low preference for base pay, then they will demonstrate a high level of hope and vice versa, since the relationship is inversely related. In the same way, if respondents exhibit a low preference for benefits, they will also demonstrate a high level of optimism and vice versa. Whilst these correlations were statistically significant, they were not found to be practically significant as they were below the practically significant level of 0.30 (Gravetter \& Wallnau, 2013).

What can be concluded from Table 4 is that there are statistically significant correlations between satisfaction with base pay and hope, as well as satisfaction with base pay and total PsyCap. Furthermore, there is a statistically significant correlation between satisfaction with performance and career management and self-efficacy, hope, optimism and total PsyCap. Finally, the table indicates that there is a statistically significant correlation between satisfaction with work-life integration, as well as total reward satisfaction, with levels of optimism. Whilst these correlations have been found to be statistically significant, practical significance was not proven. It is important to note that all of the above correlations are positive, implying that higher satisfaction with these rewards imply higher levels of the PsyCap dimensions mentioned.
TABLE 5: PCQ factors according to age.

\begin{tabular}{l|c|c}
\hline Variable & $\boldsymbol{F}$ & $\boldsymbol{p}$ \\
\hline Self-efficacy & 1.717 & 0.184 \\
\hline Hope & 1.680 & 0.191 \\
\hline Resilience & 3.979 & $0.021^{*}$ \\
\hline Optimism & 0.960 & 0.386 \\
\hline PsyCap & 0.506 & 0.604 \\
\hline
\end{tabular}

PCQ, Psychological Capital Questionnaire ${ }^{*} p<0.05=$ statistically significant.

TABLE 6: Scheffé's test and Cohen's d for resilience, according to age.

\begin{tabular}{lcccc}
\hline Age 1 & Age 2 & Difference $\mathbf{M}_{\mathbf{1}}-\mathbf{M}_{\mathbf{2}}$ & Scheffé $\mathbf{p}$ & Cohen's d \\
\hline $18-38$ & $39-48$ & -0.47 & $0.042^{*}$ & 0.68 \\
$18-38$ & $49+$ & -0.43 & $0.041^{*}$ & 0.60 \\
$39-48$ & $49+$ & 0.05 & 0.950 & $n / a$ \\
\hline
\end{tabular}

${ }^{*} p<0.05=$ statistically significant; $0.50<|d|<0.80=$ medium practically significant effect.

\section{Impact of demographic variables on PCQ factors using ANOVA} Age and PCQ factors

Table 5 shows the ANOVA results for the factors of the PCQ according to age. This was the only demographic variable that displayed a statistically significant difference between factors of the PCQ. From Table 5 it is evident that there are statistically significant differences in terms of resilience between respondents according to age, as the $p$-value is lower than 0.05 .

Table 6 illustrates the results of Scheffé's post-hoc test for the PCQ resilience factor according to age. The differences between resilience and the age groups 18-38 and 39-48 and between age categories 18-38 and 49+ are statistically significant $(p<0.05)$. Cohen's $d$ was calculated to determine practical significance and a medium level of practical significance $(0.50<|\mathrm{d}|<0.80)$ was found.

\section{Impact of demographic variables on RPQ factors using ANOVA}

Table 7 shows the ANOVA results for the preference and satisfaction factors of the RPQ according to various 
TABLE 7: RPQ factors according to demographic variables.

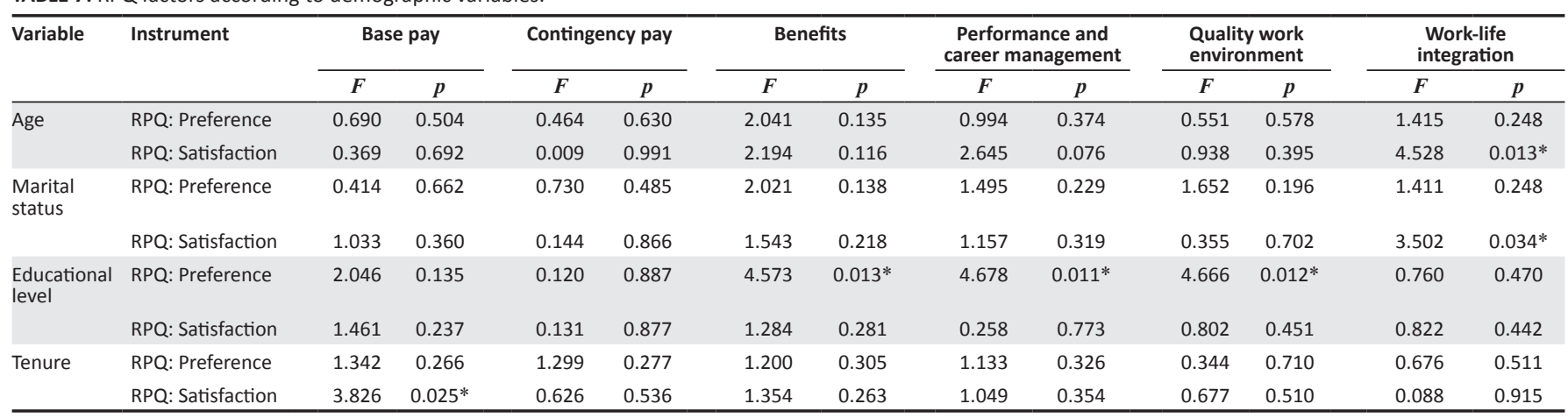

PCQ, Psychological Capital Questionnaire; RPQ, Reward Preferences Questionnaire

$* p<0.05=$ statistically significant.

TABLE 8: Scheffé's test and Cohen's d for satisfaction with work-life integration, according to age.

\begin{tabular}{lcccc}
\hline Age 1 & Age 2 & Difference $\mathbf{M}_{\mathbf{1}}-\mathbf{M}_{\mathbf{2}}$ & Scheffé $\mathbf{p}$ & Cohen's d \\
\hline $18-38$ & $39-48$ & -0.31 & 0.299 & $\mathrm{n} / \mathrm{a}$ \\
$18-38$ & $49+$ & -0.53 & $0.014^{*}$ & 0.74 \\
$39-48$ & $49+$ & -0.23 & 0.365 & $\mathrm{n} / \mathrm{a}$ \\
\hline
\end{tabular}

demographic variables. Statistically significant relationships are represented by $p$-values less than 0.05 .

It is evident that there are statistically significant differences between satisfaction with work-life integration both according to age and marital status, between a preference for benefits, preference for performance and career management and preference for a quality working environment according to educational level, and between satisfaction with base pay and tenure. The following sub-sections will expand on these differences.

\section{Age and RPQ factors}

Scheffé's test (Table 8) shows that there is a statistically significant difference between the age groups 18-38 and $49+$ for satisfaction with work-life integration as the $p$-value is below 0.05 . Once Cohen's $d$ was calculated, it was revealed that there was a medium level of practical significance $(0.50<|\mathrm{d}|<0.80)$ between individuals of these two age groups for this factor.

\section{Marital status and RPQ factors}

Table 9 indicates the results of the Scheffé's post-hoc test, which revealed that there is a statistically significant difference between respondents who are married or living together and those who are single in terms of their satisfaction with work-life integration ( $p=0.034)$. Cohen's $d$ confirmed that this difference holds a medium practical significance $(0.50<$ $|\mathrm{d}|<0.80)$.

\section{Educational level and RPQ factors}

Table 10 displays the results of the Scheffé's post-hoc test with regard to respondents' preferences for benefits, performance and career management and a quality work environment. It is apparent that there is a significant difference for preference for benefits between respondents who possess a diploma or degree and those with a postgraduate qualification.
TABLE 9: Scheffé's test and Cohen's d for satisfaction with work-life integration, according to marital status.

\begin{tabular}{llccc}
\hline Marital status 1 & Marital status 2 & $\begin{array}{c}\text { Difference } \\
\mathbf{M}_{1}-\mathbf{M}_{2}\end{array}$ & Scheffé $\mathbf{p}$ & Cohen's d \\
\hline $\begin{array}{l}\text { Married/Living } \\
\text { together }\end{array}$ & Single & 0.45 & $0.034^{*}$ & 0.62 \\
$\begin{array}{l}\text { Married/Living } \\
\text { together }\end{array}$ & $\begin{array}{l}\text { Divorced/separated/ } \\
\text { widowed }\end{array}$ & 0.12 & 0.794 & $\mathrm{n} / \mathrm{a}$ \\
$\begin{array}{l}\text { Single } \\
\text { Divorced/separated/ } \\
\text { widowed }\end{array}$ & -0.32 & 0.316 & $\mathrm{n} / \mathrm{a}$ \\
\hline
\end{tabular}

${ }^{*} p<0.05=$ statistically significant $; 0.50<|d|<0.80=$ medium practically significant effect.

Cohen's $d$ revealed that this difference holds a large practical significance ( $|\mathrm{d}|>0.80)$.

From Table 10 it is seen that there is a significant difference between those respondents with a diploma or degree and those with a postgraduate qualification with regard to their preference for performance and career management. A medium practical significance was found $(0.50<|\mathrm{d}|<0.80)$.

Finally, there is a statistically significant difference between respondents with a diploma or degree and those with a postgraduate qualification with regard to their preference for a quality work environment as a reward. This difference also holds a medium practical significance $(0.50<|\mathrm{d}|<0.80)$.

\section{Tenure and RPQ factors}

Scheffé's post-hoc test, shown in Table 11, indicates that there is a statistically significant difference between respondents with 4-10 years of service and those with more than 10 years of service $(p=0.025)$ in terms of their satisfaction with base pay. Cohen's $d$ indicates a medium practical significance $(0.50<$ $|\mathrm{d}|<0.80)$.

\section{Impact of demographic variables on PCQ and RPQ factors using $t$-tests Sector and PCQ and RPQ factors}

Two sample independent $t$-tests were used to identify sector differences for scores on each of the factors across the PCQ and the RPQ. It is clear from Table 12 that a number of statistically significant relationships exist between the factors of the RPQ and the public and private sector nurses $(p<0.05)$. For each of the differences discussed below, the direction of the differences has been obtained from the mean scores shown in Table 12. 
TABLE 10: Scheffé's test and Cohen's d for a preference for benefits, performance and career management and a quality work environment, according to educational level.

\begin{tabular}{|c|c|c|c|c|c|}
\hline Variable & Education level 1 & Education level 2 & Difference $M_{1}-M_{2}$ & Scheffé $p$ & Cohen's d \\
\hline \multirow[t]{3}{*}{ Benefits } & Matric or less & Diploma/degree & 0.05 & 0.967 & $\mathrm{n} / \mathrm{a}$ \\
\hline & Matric or less & Postgraduate & -0.55 & 0.071 & $\mathrm{n} / \mathrm{a}$ \\
\hline & Diploma/degree & Postgraduate & -0.60 & $0.015^{*}$ & 0.80 \\
\hline \multirow[t]{3}{*}{ Performance and career management } & Matric or less & Diploma/degree & 0.21 & 0.344 & $\mathrm{n} / \mathrm{a}$ \\
\hline & Matric or less & Postgraduate & -0.24 & 0.407 & $\mathrm{n} / \mathrm{a}$ \\
\hline & Diploma/degree & Postgraduate & -0.46 & $0.014 *$ & 0.76 \\
\hline \multirow[t]{3}{*}{ Quality work environment } & Matric or less & Diploma/degree & 0.05 & 0.923 & $\mathrm{n} / \mathrm{a}$ \\
\hline & Matric or less & Postgraduate & -0.33 & 0.086 & $\mathrm{n} / \mathrm{a}$ \\
\hline & Diploma/degree & Postgraduate & -0.37 & $0.013^{*}$ & 0.78 \\
\hline
\end{tabular}

${ }^{*} p<0.05$ = statistically significant; $0.50<|d|<0.80=$ medium practically significant effect; $|\mathrm{d}|>0.80=$ large practically significant effect.

TABLE 11: Scheffé's test and Cohen's d for satisfaction with base pay, according to tenure.

\begin{tabular}{|c|c|c|c|c|}
\hline Tenure 1 & Tenure 2 & Difference $M_{1}-M_{2}$ & Scheffé $p$ & Cohen's d \\
\hline $0-4$ years & $4-10$ years & -0.29 & 0.298 & $n / a$ \\
\hline $0-4$ years & $10+$ years & 0.18 & 0.544 & $\mathrm{n} / \mathrm{a}$ \\
\hline $4-10$ years & $10+$ years & 0.47 & $0.025 *$ & 0.67 \\
\hline
\end{tabular}

$* p<0.05$ = statistically significant; $0.50<|d|<0.80=$ medium practically significant effect.

TABLE 12: t-Tests for RPQ and PCQ, according to sector.

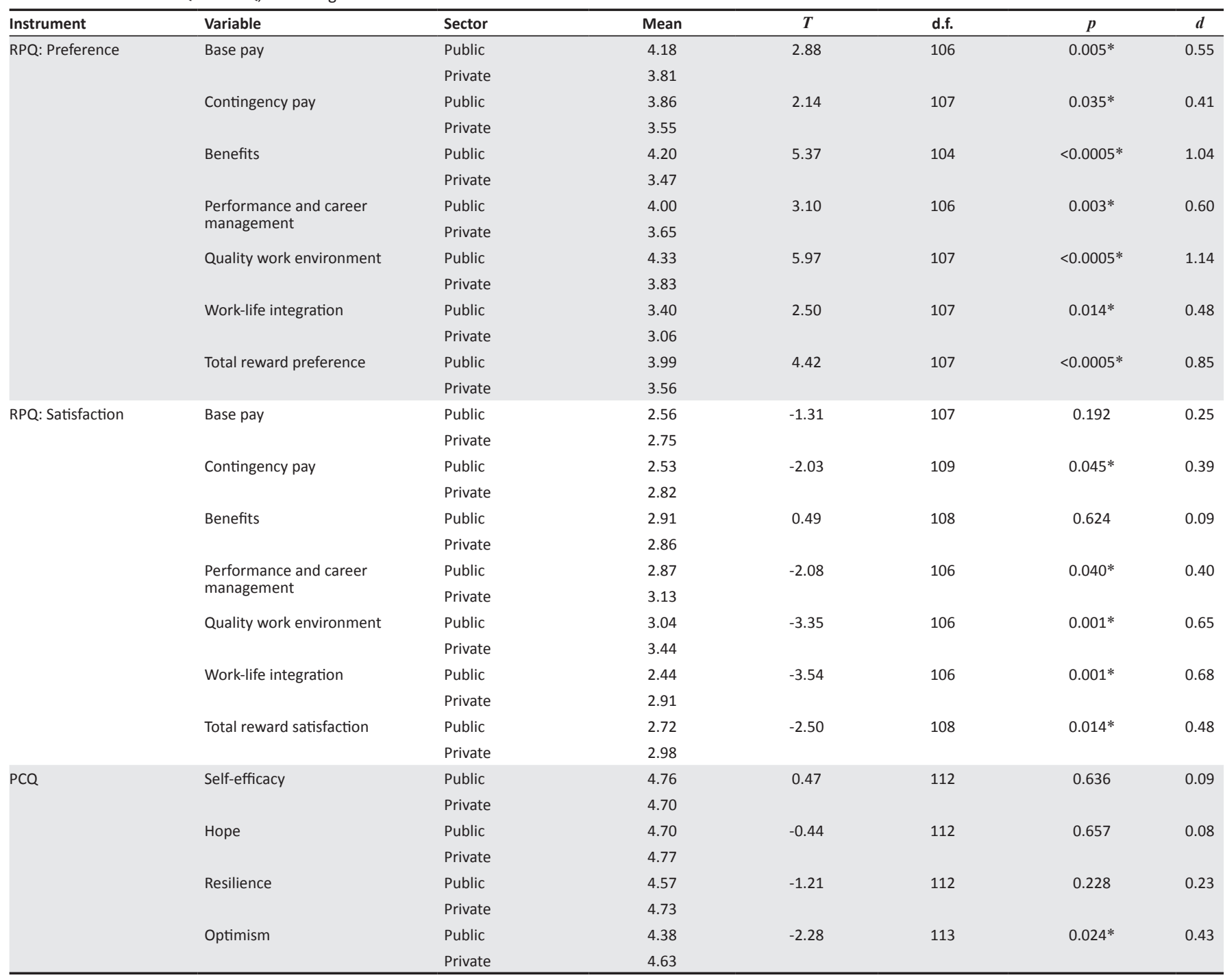

PCQ, Psychological Capital Questionnaire; RPQ, Reward Preferences Questionnaire

${ }^{*} p<0.05=$ statistically significant; $0.20<|d|<0.50=$ small practically significant effect; $0.50<|d|<0.80=$ medium practically significant effect; $\mid$ d $\mid>0.80=$ large practically significant effect.

With regard to preference for base pay, respondents within the public sector had a stronger preference for this factor than those in the private sector. Cohen's $d$ revealed a medium practical significance between the two sectors $(0.50<|\mathrm{d}|<0.80)$. 
Public sector nurses also had a greater preference for contingency pay than those in the private sector and a small practical significance was revealed $(0.20<|\mathrm{d}|<0.50)$.

The public sector nurses prefer benefits as a reward compared to the public sector nurses. Cohen's $d$ indicated a large practical significance $(|\mathrm{d}|>0.80)$. Regarding preference for performance and career management, the public sector respondents have a stronger preference for this particular reward than those in the private sector. Cohen's $d$ highlights that this difference holds a medium practical significance $(0.50<|\mathrm{d}|<0.80)$.

The public sector respondents prefer the reward of a quality work environment more than the private sector nurses; this difference was of a large practical significance ( $|\mathrm{d}|>0.80)$. It is apparent that the public sector respondents prefer work-life integration as a reward more than private sector respondents, with this difference holding a small practical significance $(0.20<|\mathrm{d}|<0.50)$. Finally, public sector respondents place an overall greater preference on their levels of total rewards than the private sector respondents, with this holding a large practical significance $(|\mathrm{d}|>0.80)$.

Table 12 also highlights that the public sector is significantly less satisfied with the levels of contingency pay, performance and career management, quality of work environment and work-life integration provided to them compared to the private sector. The first two differences hold a small practical significance $(0.20<|\mathrm{d}|<0.50)$ whereas the latter two hold a medium practical significance $(0.50<|\mathrm{d}|<0.80)$. Regarding total reward satisfaction, nurses within the private sector are more satisfied with their current rewards than nurses in the public sector. This holds a small practically significant difference $(0.20<|d|<0.50)$.

From Table 12 it is apparent that the only statistically significant relationship between sector and the subscales of the PCQ is between sector and levels of optimism. Respondents within the private sector have higher scores on optimism than those within the private sector. Cohen's $d$ indicates a small practical significance $(0.20<|\mathrm{d}|<0.50)$.

\section{Job level and RPQ and PCQ factors}

Two sample independent $t$-tests were used to identify job level differences for scores on each of the factors across the PCQ and the RPQ. No differences were found; therefore, this table has not been included.

\section{Discussion}

\section{Outline of the results}

The key research objective of this study was to establish whether a relationship exists between PsyCap and both reward preferences and reward satisfaction, specifically within the medical industry. The impact of demographic variables on these constructs was also investigated. As this research was conducted within five medical institutions within the Nelson Mandela Metropole, generalisations from these results to the broader South African population are not necessarily appropriate.

\section{Relationship between PsyCap and reward preferences}

The relationships shown in Table 3 could be viewed as inferring that nurses who are not highly hopeful and optimistic have a greater preference for receiving base pay and benefits as rewards respectively. The authors note that both base pay and benefits form part of fixed pay. This suggests that those nurses who are not highly hopeful and optimistic prefer fixed pay rather than the more 'risky' variable pay, perhaps because they are not optimistic for the future or hopeful that their performance would be of a high enough standard to receive performance-related variable pay. However, more research is required in this regard in order to make conclusive inferences.

\section{Relationship between PsyCap and reward satisfaction}

The findings provided in Table 8 suggest that nurses will be more satisfied with their total rewards package, and specifically the work-life integration and performance and career management options provided to them, when they are highly optimistic. Inversely, this finding suggests that they will be less optimistic when they are dissatisfied with their total rewards package and both work-life integration and performance and career management. This finding correlates with literature, as individuals who see the good in their current situations (i.e. are optimistic) will be more satisfied with all aspects of their work situations, such as with their reward packages (Avey, 2014). Dissatisfaction with their levels of rewards may jade employees, resulting in lower levels of optimism.

Additionally, based on Table 4 the authors note that when nurses are hopeful and have positive expectations both of themselves and their employers, then it is more likely that they will be satisfied with both base pay and their performance and career management opportunities. However, due to the lack of existing research linking these constructs, further research may be required to draw a firm conclusion.

Furthermore, the findings in this table highlight the significance of one particular non-financial reward, namely performance and career management, in impacting nurses' levels of PsyCap. Due to the fact that nurses having high levels of PsyCap would hold many benefits for patients (Othman et al., 2013; Peng et al., 2013), hospitals and other healthcare providers should want to develop higher levels of PsyCap within their employees. Thus, this finding is of value because it implies that if hospitals and other healthcare providers develop clear performance and career management paths with which their nurses are satisfied, then higher levels of PsyCap may occur as a result.

\section{Impact of age on reward satisfaction and PsyCap}

The findings provided in Table 4 may suggest that younger nurses are not receiving enough allowance for work- 
life integration, despite the fact that Snelgar et al. (2013), Nienaber et al. (2011) and Von Bonsdorff (2011) state that younger employees typically show a preference for work-life integration as a reward. Although the present study did not indicate any significant differences between age and nurses' preferences for work-life integration, the present findings taken together with those put forward by Snelgar et al. (2013) imply that not receiving sufficient opportunities for work-life integration would lead to dissatisfaction amongst younger respondents.

The authors suggest that the resilience differences across age as shown in Table 6 may be due to the fact that as individuals get older they are likely to mature and learn to be more resilient. Older employees may have experienced more difficulties in their working careers than younger employees and thus may have had to develop their levels of resilience in order to cope with such challenging experiences. This aligns with the suggestion put forth by Rauschenbach et al. (2012) that older employees may exhibit greater resilience due to their wealth of work experience. This study, like that of Harris (2012), does not illustrate any significant differences in levels of PsyCap according to age.

\section{Impact of marital status on reward satisfaction}

The authors propose that the difference in a preference for work-life integration between individuals who are married or living together compared to single individuals (see Table 9) may be explained by the fact that married individuals enjoy work-life integration as a reward since they have a family or a spouse to share their lives with. As proposed by Greenhaus, Callanan and Godshalk (2010), spouses or partners may be available to assist in alleviating stress due to the balancing of work with family commitments. This aligns with what was suggested by Nienaber et al. (2011).

\section{Impact of educational level on reward preferences}

The authors believe that the differences discovered regarding reward preferences across educational level (Table 10) may occur due to the expectations that individuals with postgraduate qualifications have regarding their rewards. It is likely that the higher an employee's qualification, the larger the reward he or she will expect to receive, including the provision of adequate resources, quality co-workers and a comfortable work environment. In addition, nurses who have completed postgraduate studies are more likely to have a different mindset through being more analytical in terms of their thinking and better able to apply their skills compared to those who only have an undergraduate qualification. The authors suggest that such nurses are more likely to be confident in their abilities to acquire new knowledge and implement it correctly because of the intensity of their postgraduate studies. This, therefore, links to performance and career management as these individuals are more likely to be open to further development and training. These findings align with those of Nienaber et al. (2011) regarding educational level and reward preferences.

\section{Impact of tenure on reward satisfaction}

Based on the findings presented in Table 11 the authors suggest that senior nurses may not be receiving base pay increases at the rate at which they expect. This is supported by the research put forward by Von Bonsdorff (2011). However, more research is required in this regard to draw a firm conclusion.

\section{Impact of sector on reward preferences, reward satisfaction and PsyCap}

It is interesting to note that whilst the public sector nurses place a greater preference on the various rewards measured compared to the private sector nurses, it is the nurses of the private sector that are more satisfied overall with their current level of rewards (see Table 12). This implies that managers at the public hospital under study need to re-evaluate both the financial and non-financial rewards provided to their nurses, in order to improve their nurses' levels of satisfaction thereof. Since Snelgar et al. (2013) found that performance and career management was the reward that most strongly motivates employees, it can be further highlighted that this non-financial reward should be particularly focused on when re-evaluating the rewards given to public sector nurses.

As seen in Table 12, nurses in the private sector were found to have higher levels of optimism compared to those in the public sector. This could be due to the fact that the facilities within the private sector medical institutions studied may be significantly better and more technologically advanced than those in the public sector, resulting in private sector nurses feeling more optimistic about the level of care that they are able to provide when treating patients. The authors note that this is likely to impact the manner in which, and rate at which, their patients may recover.

\section{Practical implications}

As previously highlighted, high levels of PsyCap in nursing staff will prove beneficial to the patients they treat as well as the medical institutions at which they work; for this reason, the development of PsyCap within nurses is imperative. However, since the present findings suggest that the majority of the sample have high levels of PsyCap, increasing PsyCap need not be an immediate concern for the medical institutions under study.

As the level of reward satisfaction experienced by nurses is likely to impact on the level of healthcare provided to patients, it is essential that medical institutions take the reward preferences and satisfaction of their nurses into account in order to increase their levels of PsyCap. This can be done by considering the differing reward preferences of staff when designing reward packages. For example, the authors note that the sample shows a preference for components of fixed pay (i.e. benefits and base pay); therefore it is within the relevant organisation's best interests not to incorporate variable pay (i.e. contingency pay) into reward packages as this may result in demotivating employees. Furthermore, the study revealed that younger employees were dissatisfied 
with their allowance for work-life integration; the institutions in the sample could make provisions to address this by providing more flexitime or personal days. Moreover, medical institutions should take into account the particular life stage that their employees are in when designing their relevant rewards packages, as the study also reveals that married individuals have a greater preference for work-life integration than their single counterparts. As the majority of the sample has some form of tertiary education, the organisations under study should reward their employees for this accordingly. The study reveals that the higher the qualification, the greater the preference for benefits, quality working environment and performance and career management, thus suggesting that these individuals have higher expectations of the organisation and want to be challenged and developed further. The organisations under study should make provisions for this by regularly providing opportunities for training and development, keeping the working environment up to a high standard and consistently assessing how satisfied employees are with their specific benefits.

Based on the findings, it is evident that individuals with a shorter tenure (4-10 years) are more satisfied with their pay than those with 10 or more years of service. Therefore, whilst medical institutions may initially be meeting the expectations of their employees, employees with longer service might not have their pay frequently reviewed and do not receive the level of pay they had hoped for. The authors suggest that the organisations under study introduce a long service bonus every 5 or 10 years to create a stronger link in the minds of their employees between their length of service and pay. Finally, whilst public sector nurses show the greatest preference for rewards, nurses in the private sector are more satisfied with their rewards. Therefore, the authors suggest that medical institutions in the public sector make every effort to improve the working conditions of their nurses by ensuring that they are medically safe and hygienic and that their nurses have all their necessary equipment. Moreover, this sector could provide a form of 'pay bonus' due to the high-risk environment that the employees in the public sector may be exposed to. Overall, management in the public sector should assess employees' training and development opportunities and work-life integration as well and attempt to align these better with the needs of employees in order to improve their levels of satisfaction.

This study serves as a guideline concerning the reward preferences of nurses employed by medical institutions within the Nelson Mandela Metropole. Importantly, it suggests that medical institutions should turn their attention to the satisfaction that their employees experience with regard to their rewards and attempt to increase these levels of satisfaction. This is due to the fact that the majority of the correlations in this study existed between reward satisfaction subscales and PsyCap subscales, thus suggesting that PsyCap factors may be influenced through employees' levels of reward satisfaction. Bussin (2011) recommends ensuring that both internal and external equity exists in relation to rewards, which is likely to lead to satisfaction in employees with regard to their level of base pay. In so doing, high levels of PsyCap may be maintained, resulting in more productive, satisfied, committed employees with lower levels of burnout. It is also important to note that by providing employees with their respective rewards preferences, it is likely that they will be more satisfied with their rewards as they will be tailored according to their individual preferences.

\section{Limitations and recommendations}

The sample size of this study was deemed adequate by the authors' statistician; however, the response rate was only $42 \%$, which the authors deem a limitation to the study. As the authors were reliant on managers to distribute the questionnaires within the respective medical institutions, they had little control over how and when the questionnaires were distributed, as well as how the questionnaires were completed. Although written instructions were provided to respondents, in many cases they completed the RPQ incorrectly by leaving out questions, thus indicating that a misunderstanding occurred.

Welman et al. (2005) refer to socially desirable responses. This occurs when respondents answer in a way that is overly positive in order to provide answers that they believe to be socially desirable. Since the majority of respondents indicated that they have high levels of PsyCap, it is possible that the responses they provided were socially desirable, thus creating a limitation to this study. In future, this could be overcome by encouraging respondents to be as honest in their answers as possible and placing a greater emphasis on the fact that responses are anonymous and will be treated as confidential.

\section{Future directions}

As previously mentioned, the sample size for this study was adequate; however, the authors recommend that in future the study be expanded to include more respondents from other provinces in more than just the line of nursing (i.e. include doctors, specialists, radiographers), so that the findings can be generalised to the broader medical field within South Africa. Furthermore, the authors recommend investigating correlations between PsyCap and satisfaction with rewards in greater detail. As this study was exploratory in nature, it cannot prove beyond all doubt that the findings are absolute. The authors recommend that future studies investigate the rewards that specifically serve to attract, retain and motivate nurses. The authors believe that interesting correlations may emerge between nurses' levels of PsyCap and the rewards that best attract, retain and motivate them.

\section{Conclusion}

This study focused on the relationship between PsyCap and both reward preferences and reward satisfaction within the 
medical industry in the Nelson Mandela Metropole. This focus was chosen as there were, to date, no studies linking these constructs. Furthermore, there has been limited research within the South African context relating both to PsyCap and reward preferences in general.

The findings of this study are therefore of importance as they contribute to the body of empirically tested PsyCap and reward preferences knowledge within the South African context. This study was the first of its kind to be conducted in South Africa, to date, specifically within the medical field. The results hold important implications for medical institutions. This investigation has provided interesting and valuable insight into whether PsyCap influences nurses' reward preferences and their satisfaction therewith. As some of the findings were inconclusive, more research is required to fully explore this topic.

\section{Acknowledgements Competing interests}

The authors declare that they have no financial or personal relationships that may have inappropriately influenced them in writing this article.

\section{Authors' contributions}

S.A.S. (Nelson Mandela Metropolitan University) completed this research for her Honours treatise in partial fulfilment of her BA Honours degree in Industrial and Organisational Psychology. M.R. (Nelson Mandela Metropolitan University) was her supervisor. S.A.S was primarily responsible for the research, including compiling the literature review, conducting the research amongst the medical institutions under study and discussing the results and implications. M.R. assisted with the data analysis, overall editing and coauthoring of this manuscript.

\section{References}

Achievement Awards Group. (2008). Total rewards. Retrieved June 13, 2014, from http://www.awards.co.za

Allen, R.S., \& Helms, M.M. (2001). Reward practices and organizational performance. Compensation Benefits Review, 33, 74-80. http://dx.doi.org/10.1177/08863680 122098450

Ardichvili, A. (2011). Invited reaction: Meta-analysis of the impact of Psychological Capital on employee attitudes, behaviours and performance. Human Resource Development Quarterly, 22(5), 153-156. http://dx.doi.org/10.1002/hrdq.20071

Avey, J.B. (2014). The left side of Psychological Capital: New evidence on the antecedents of PsyCap. Journal of Leadership \& Organizational Studies, 21(2), 141-149. http://dx.doi.org/10.1177/1548051813515516

Avey, J.B., Luthans, F., \& Jensen, S.M. (2009). Psychological Capital: A positive resource for combating employee stress and turnover. Human Resource Management 48(5), 677-693. http://dx.doi.org/10.1002/hrm.20294

Avey, J.B., Reichard, R.J., Luthans, F., \& Mhatre, K.H. (2011). Meta-analysis of the impact of positive Psychological Capital on employee attitudes, behaviors, and performance. Human Resource Development Quarterly, 22(2), 127-152. http:// performance. Human Resource
dx.doi.org/10.1002/hrdq.20070

Bandura, A. (1982). Self-efficacy mechanism in human agency. American Psychologist 37(2), 122-147. http://dx.doi.org/10.1037/0003-066X.37.2.122

Bešević-Ćomić, V., Bosankić, N., \& Draganović, S. (2014). Burnout syndrome and selfefficacy among nurses. Scripta Medica, 45(1), 26-29.

Boyd, B.K., \& Salamin, A. (2001). Strategic reward systems: A contingency model of pay system design. Strategic Management Journal, 22(8), 777-792. http://dx.doi. org/10.1002/smj.170

Bussin, M. (2011). The remuneration handbook for Africa. Randburg, South Africa: Knowres Publishing.
Chen, H.M., \& Hsieh, Y.H. (2006). Key trends of the total reward system in the 21st century Compensation Benefits Review, 38, 64-70. http://dx.doi. org/10.1177/0886368706292542

Chiang, F.F.T., \& Birtch, T.A. (2012). The performance implications of financial and nonfinancial rewards: An Asian Nordic comparison. Journal of Management Studies, 49(3), 538-570. http://dx.doi.org/10.1111/j.1467-6486.2011.01018.x

Chiu, R.K., Luk, V.W.M., \& Tang, T.L.P. (2002). Retaining and motivating employees: Compensation preferences in Hong Kong and China. Personnel Review, 31(4), 402-431. http://dx.doi.org/10.1108/00483480210430346

Dewhurst, M., Guthridge, M., \& Mohr, E. (2009). Motivating people: Getting beyond money. McKinsley Quarterly, November, 1-5.

Ehlers, V.J., \& Oosthuizen, M.J. (2011). Factors influencing the retention of registered nurses in the Gauteng Province of South Africa. Curationis, 34(1), 1-8. http:// dx.doi.org/10.4102/curationis.v34i1.16

Fin24. (2014a). Private hospital staff: We are money-making slaves. Retrieved January 09, 2014, from http://www.fin24.com/Money/Health/Private-Hospital-Staff-Weare-money-making-slaves-20140919

Fin24. (2014b). Payment of private hospital staff questioned. Retrieved January 09 2014, from http://www.fin24.com/MyFin24/Payment-of-private-hospital-staffquestioned-20140909

Fracaro, K. (2001). Optimism on a rainy day. Supervision, 62(5), 5-8.

Görgens-Ekermans, G., \& Herbert, M. (2013). Psychological capital: Internal and external validity of the Psychological Capital Questionnaire (PCQ-24) on a South African sample. SA Journal of Industrial Psychology, 39(2), 1-12. http://dx.doi. org/10.4102/sajip.v39i2.1131

Gravetter, F.J., \& Wallnau, L.B. (2013). Statistics for the behavioral sciences. (9th edn.). New York, NY: Wadsworth Cengage Learning.

Greenhaus, J.H., Callanan, G.A., \& Godshalk, V.M. (2010). Career management. (4th edn.). California: Sage.

Harris, C. (2012). Relationships between Psychological Capital, work engagement and organisational citizenship behaviour in South African automotive dealerships. organisational citizenship behaviour in South African automotive dealerships.
Unpublished doctoral dissertation, Department of Industrial and Organisational Unpublished doctoral dissertation, Department of Industrial and Organisational
Psychology, Nelson Mandela Metropolitan University, Port Elizabeth, South Africa.

Kaliprasad, M. (2006). Attracting, retaining and motivating capable people. Cost Engineering, 48(6), 20-26.

Kwon, J., \& Hein, P. (2013). Employee benefits in a total rewards framework. Benefits Quarterly, 29(1), 32-38.

Lazarus, R.S. (1999). Hope: An emotion and a vital coping resource against despair Social Research, 66, 665-669.

Linkow, P. (2006). Winning the competition for talent. Workspan, 10(6), 29-32.

Luthans, B.C., Luthans, K.W., \& Avey, J.B. (2014). Building the leaders of tomorrow: The development of academic Psychological Capital. Journa of Leadership \& Organizational Studies, 21(2), 191-199. http://dx.doi. org/10.1177/1548051813517003

Luthans, F. (2002a). The need for and meaning of positive organizational behavior Journal of Organizational Behavior, 23, 695-706. http://dx.doi.org/10.1002/job.165

Luthans, F. (2002b). Positive organizational behavior: Developing and managing psychological strengths. Journal of Management Executive, 16(1), 57-72. http:// dx.doi.org/10.5465/AME.2002.6640181

Luthans, F. (2012). Psychological Capital: Implications for HRD, retrospective analysis, and future directions. Human Resource Development Quarterly, 23(1), 1-8. http://dx.doi.org/10.1002/hrdq.21119

Luthans, F., Avey, J.B., Avolio, B.J., \& Peterson, S.J. (2010). The development and resulting performance impact of positive Psychological Capital. Human Resource Development Quarterly, 21(1), 41-67. http://dx.doi.org/10.1002/hrdq.20034

Luthans, F., Avolio, B.J., \& Avey, J.B. (2007). Psychological Capital Questionnaire for researchers. Retrieved January 09, 2014, from http://www.mindgarden.com/ products/pcq.htm

Luthans, F., Norman, S.M., Avolio, B.J., \& Avey, J.B. (2008). The mediating role of Psychological Capital in the supportive organizational climate-employee performance relationship. Journal of Organizational Behavior, 29, 219-238. http://dx.doi.org/10.1002/job.507

Luthans, F., \& Youssef, C.M. (2007). Emerging positive organizational behaviour. Journal of Management, 33(3), 321-349. http://dx.doi.org/10.1177/0149206307300814

Malhotra, N.K. (2010). Marketing research: An applied orientation. (6th edn.). Upper Saddle River, NJ: Pearson Education Inc. http://dx.doi.org/10.1108/S1548 6435(2010)0000007016

Moore, A., \& Bussin, M. (2009). Reward preferences for generations in selected ICT companies. Unpublished dissertation, University of Johannesburg, Johannesburg, South Africa. Retrieved March 04, 2014, from www.sajhrm.co.za/index.php/ sajhrm/article/view/606/839

Nienaber, N., Bussin, M.H.R., \& Henn, C. (2011). The relationship between personality types and reward preferences. Acta Commercii, 1, 1-21.

Othman, N., Ghazali, Z., \& Ahmad, S. (2013). Resilience and work engagement: A stitch to nursing care quality. Journal of Global Management, 6(1), 40-48.

Peng, J., Jiang, X., Zhang, J., Xiao, R., Song, Y., Feng, X. et al. (2013). The impact of Psychological Capital on job burnout of Chinese nurses: The mediator role of Organizational Commitment. Public Library of Science One, 8(12), 1-7. http:// dx.doi.org/10.1371/journal.pone.0084193

Rauschenbach, C., Göritz, A.S., \& Hertel, G. (2012). Age stereotypes about emotional resilience at work. Educational Gerontology, 38, 511-519. http://dx.doi.org/10.1 080/03601277.2011.567187 
Scheier, M.F., \& Carver, C.S. (1985). Dispositional optimism and physical wellbeing: The influence of generalized outcome expectancies on health. Journal of being: The influence of genality, 55(2), 171-210.
Personat

Schneider, S.L. (2001). In search of realistic optimism: Meaning, knowledge, and warm fuzziness. American Psychologist, 56, 250-263. http://dx.doi.org/10.1037/0003066x.56.3.250

Schoeman, J.D. (2012). The relationship between work place well-being, Psychological Capital and work place trust. Unpublished doctoral dissertation, Department of Industrial and Organisational Psychology, Nelson Mandela Metropolitan University, Port Elizabeth, South Africa.

Snelgar, R.J., Renard, M., \& Venter, D. (2013). An empirical study of the reward preferences of South African employees. SA Journal of Human Resource Management, 11(1), 84-97. http://dx.doi.org/10.4102/sajhrm.v11i1.351

Snyder, C.R. (2002). Hope theory: Rainbows in the mind. Psychological Inquiry, 13(4), 249-275. http://dx.doi.org/10.1207/S15327965PLI1304_01

Stajkovic, A.D., \& Luthans, F. (1998). Social cognitive theory and self efficacy: Going beyond traditional motivational and behavioral approaches. Organizational Dynamics, 26, 62-74. http://dx.doi.org/10.1016/S0090-2616(98)90006-7
Thumbran, R.S. (2010). Utilizing non-financial rewards as a competitive advantage in attracting and retaining employees. Unpublished dissertation, Gordon Institute of
Business Science, University of Pretoria, Pretoria, South Africa. Retrieved February 28, 2014, from www.upetd.up.ac.za/thesis/

Von Bonsdorff, M.E. (2011). Age-related differences in reward preferences. The International Journal of Human Resource Management, 22(6), 1262-1276. http:// dx.doi.org/10.1080/09585192.2011.559098

Wang, Y., Chang, Y., Fu, J., \& Wang, L. (2012). Work-family conflict and burnout among Chinese female nurses: the mediating effect of psychological capital. BMC Public Health, 12(915), 1-8. http://dx.doi.org/10.1186/1471 2458-12-915

Welman, C., Kruger, S.J., \& Mitchell, B. (2005). Research methodology. (3rd edn.). Cape Town, South Africa: Oxford University Press.

WorldatWork. (2006). The "it" factor: A new Total Rewards Model leads the way. Retrieved June 17, 2014, from http://www.worldatwork.org

Zobal, C. (1999). The "ideal" team compensation system - An overview, part II. Team Performance Management, 5(1), 23-45. http://dx.doi.org/10.1108/ 13527599910263125 